\title{
Risk factor investigation for cardiovascular health through WHO STEPS approach in Ardabil, Iran
}

\author{
This article was published in the following Dove Press journal: \\ Vascular Health and Risk Management \\ 8 July 2011 \\ Number of times this article has been viewed
}

\section{H Sadeghi-Bazargani ${ }^{1,2}$ \\ $\mathrm{H}$ Jafarzadeh ${ }^{3}$ \\ M Fallah ${ }^{4}$ \\ $S$ Hekmat $^{3}$ \\ J Bashiri ${ }^{3}$ \\ GH Hosseingolizadeh ${ }^{3}$ MS Soltanmohammadzadeh ${ }^{3}$ \\ A Mortezazadeh ${ }^{3}$ \\ A Shaker ${ }^{3}$ \\ M Danehzan ${ }^{3}$ \\ A Zohouri ${ }^{3}$ \\ O Khosravi ${ }^{3}$ \\ R Nasimidoust ${ }^{3}$ \\ N Malekpour ${ }^{3}$ \\ E Kharazmi ${ }^{4}$ \\ M Babaei ${ }^{3}$ \\ $M$ Nadirmohammadi ${ }^{3}$ \\ H Mashhadi-Abdollahi ${ }^{5}$ \\ 'Neuroscience Research Center, \\ ${ }^{2}$ Statistics and Epidemiology \\ Department, Faculty of Health \\ and Nutrition, Tabriz University \\ of Medical Sciences, Tabriz, Iran; \\ ${ }^{3}$ Public Health Department, Ardabil \\ University of Medical Sciences, \\ Ardabil, Iran; ${ }^{4}$ Tampere School of \\ Public Health, University of Tampere, \\ Tampere, Finland; ${ }^{5}$ National Public \\ Health Management Center (NPMC), \\ Tabriz University of Medical Sciences, \\ Tabriz, Iran}

Correspondence: Hossein Mashadi Abdollahi

Tabriz University of Medical Sciences,

Golgasht Street, Tabriz, Iran

Tel +98 9144000823

Fax +984 II 3359680

Email h.abdollahimashadi@yahoo.com
Objectives: Reliable evidence is the keystone for any noncommunicable disease (NCD) prevention plan to be initiated. In this study we carried out a risk factor investigation based on the WHO Stepwise approach to Surveillance (STEPS).

Methods: The study was conducted on 1000 adults between 15 and 64 years of age living in Ardabil province, north-west Iran during 2006, based on the WHO STEPS approach to surveillance of risk factors for NCD. At this stage only the first and second steps were carried out. Data were collected through standard questionnaires and methods analyzed using STATA version 8 statistical software package.

Results: $29.0 \%$ of men and $2.6 \%$ of women were current daily tobacco smokers. The mean number of manufactured cigarettes smoked per day was 18.9 among current daily smokers. Smoking was most prevalent among men of low-income families and those of lower education. The mean body mass index (BMI) was $26.6 \mathrm{~kg} / \mathrm{m}^{2}$, and was significantly correlated with systolic blood pressure. $58.9 \%$ were overweight or obese; $18.0 \%$ had raised blood pressure and $3.7 \%$ had isolated systolic hypertension. The mean number of servings of fruit consumed per day was $1.1 ; 33.1 \%$ had low levels of activity. Combined risk factor analysis showed that $4.1 \%$ of participants were in the low-risk group (up to 5.1\% among men and 3.2\% among women). Those in the high-risk group comprised $25.6 \%$ in the 25 - to 44 -year age group and $49.7 \%$ in the 45- to 64-year age group. Mean BMI increased by age in both sexes at least at the first three decades of adult life.

Conclusion: Based on observed status of risk for cardiovascular health, burden of cardiovascular diseases is expected to increase if an effective prevention strategy is not undertaken.

Keywords: cardiovascular health, noncommunicable diseases, WHO STEPS, smoking, obesity, physical activity

\section{Introduction}

Life expectancy at birth has increased from a global average of 46 years in 1950 to 66 years in $1998 .{ }^{1}$ Along with lifestyle changes and environmental hazards, this life expectancy increase has caused an elevated rate of noncommunicable diseases (NCDs) globally but with delay in developing countries. "Of 57 million global deaths in 2008 , 36 million, or $63 \%$ were due to noncommunicable diseases. In 2008 , nearly $80 \%$ of noncommunicable disease deaths (29 million), ccurred in low- and middle-income countries with about $29 \%$ of deaths occurring before the age of 60 in these countries". ${ }^{2}$ NCDs are predicted to account for approximately three-quarters of all deaths in the developing world by the year $2020 .^{3}$

Developing countries shared $72 \%$ of 33.4 million deaths caused by NCDs during the year $2002 .{ }^{4}$ Nearly $90 \%$ of the world's total disease burden occurs in developing 
countries, while only $10 \%$ of global health expenditure is allocated in these countries. ${ }^{5}$

The NCD condition is the same for many of the WHO Eastern Mediterranean Region countries, and considering the pre-existing heavy load of infectious diseases in these countries, they are tolerating a double burden of both infectious diseases and NCDs.

Iran is known to have a good national health network. Since 1984, the primary health care system in Iran has become highly organized and efficient, resulting in a dramatic decrease in infant, maternal, and neonatal mortality rates, with an increase in population growth and life span, and a marked shift towards NCDs. Some success in controlling nutritional diseases and injuries has also been reported but there is no documentation of national success in combating major NCDs. ${ }^{6}$

Most NCDs have common preventable risk factors such as smoking, poor diet, high alcohol consumption, hypertension, sedentary lifestyle, and obesity, and for cardiovascular diseases (CVD), morbidity and mortality increase when these risk factors cluster. Reliable evidence is the keystone for any NCD prevention plan to be initiated. In this study we carried out a risk factor investigation based on the World Health Organization (WHO) STEPwise approach to Surveillance (STEPS).

\section{Methods}

This study was carried out in Ardabil in 2006. The study population comprised people aged 15 to 64 years old living in rural and urban areas of Ardabil province. Ardabil province is located in north-west Iran with a population about 1.2 million. The study was conducted based on the WHO STEPS of risk factors for NCDs. This approach uses different levels of risk factor assessment including collecting information using questionnaires (step 1), physical measurements (step 2), and taking blood samples for biomedical assessment, (step 3). Each step can include core, expanded core, and optional items. Further details can be found in Table 1 or the source reference. $^{7}$

At this stage only the first and second steps were carried out. This study was conducted by probability proportional to size (PPS) multistage stratified cluster sampling through which 50 clusters were selected. In PPS sampling, the selection probability for each element is set to be proportional to its size measure. The sampling frame of this study was based on the postal code frame of the national post office, which is updated yearly. Clusters are selected in this system based on postal code. Each address in this system is summarized in a 10-digit postal code number. In urban areas clusters comprise one to several blocks or parts of blocks. Blocks are usually attached buildings. In rural areas a cluster may comprise one to several villages or part of a village. After determining the cluster start point, enrollment and data collection started. In each cluster ten females and ten males were enrolled. These included two eligible persons in each sex and age group. This began from the household at the cluster start point and continued toward the other households until the required number of participants was enrolled. Consecutive households were selected based on geographical location of buildings to the right-hand side of each building. Data were collected based on interviews, physical examinations, and anthropometric measurements carried out by a team of trained nurses and health professionals. Research survey and examination teams visited households according to previously arranged appointments. Before the interviews or examinations by the survey teams, appointments were made by pioneer teams visiting households at least 1 day before and preferably during evenings when most people are at home. Measurements were done using calibrated and standard instruments. Height was measured with participants standing without shoes using a standard metal ruler. Weight was measured also by calibrated digital scales while light clothes were worn, in consideration of cultural principles. Waist circumference was measured at a level midway between the lower rib margin and iliac crest to the nearest $0.5 \mathrm{~cm}$. Blood pressure (BP) was measured based on WHO recommendations used in the research protocol.

Five age groups were considered for sampling: five equally distributed groups between age 15 and 64 years. This method of sampling enabled 100 participants to be included in each age and sex group, thus enrolling 1000 participants. The large sample size, the $99.5 \%$ response rate, and the sampling design and framework meant that the sample was representative of the study population. Completed questionnaires were evaluated daily, once by district supervisors and again at the provincial health center. Questionnaires with any problems or deficiencies were sent back to be rechecked and completed.

All the data were entered into the computer by one operator at a provincial health center. Data were analyzed using Stata statistical software package (v 8; Stata Corp, College Station, TX). Simple bivariate as well as multiple regression analysis was used to analyze data. Statistical significance was set at 0.05 . Priority was given to practical benefit and clinical significance in interpreting statistically 
Table I WHO STEPS approach to risk factors for noncommunicable diseases

\begin{tabular}{llll}
\hline Measures & Step I (Self report) & Step 2 (Physical examination) & Step 3 (Biochemical assessment) \\
\hline Core & $\begin{array}{l}\text { Socioeconomic and demographic variables } \\
\text { including years of education, tobacco } \\
\text { and alcohol use, physical inactivity, } \\
\text { intake of fruit and vegetables }\end{array}$ & $\begin{array}{l}\text { Measurement of weight, height, } \\
\text { waist circumference, } \\
\text { blood pressure }\end{array}$ & $\begin{array}{l}\text { Measurement of fasting } \\
\text { blood sugar, total } \\
\text { cholesterol }\end{array}$ \\
$\begin{array}{l}\text { Expanded } \\
\text { core }\end{array}$ & $\begin{array}{l}\text { Ethnicity, educational attainment, occupation, } \\
\text { income, use of smoke less tobacco, fat consumption, } \\
\text { types of physical activity, history of high blood } \\
\text { pressure, history of diabetes, treatment } \\
\text { for diabetes, treatment for high blood pressure } \\
\text { Other health-related behaviors, mental health } \\
\text { status, disability, injury }\end{array}$ & Hip circumference, pulse rate & $\begin{array}{l}\text { Fasting high-density lipoprotein, } \\
\text { cholesterol, and triglycerides }\end{array}$ \\
Optional & $\begin{array}{l}\text { Objective measurement of physical } \\
\text { activity, measurement of skin-fold } \\
\text { thickness }\end{array}$ & $\begin{array}{l}\text { Oral glucose tolerance test, } \\
\text { urine examination }\end{array}$ \\
\hline
\end{tabular}

significant data. Specific definitions in categorizing data are provided in the relevant tables. Physical activity was measured using questions on four different aspects: physical activity at the workplace, physical activity during recreation time, physical activity while traveling, and physical resting time. To define a combined risk factor index, five components were considered: (1) being a current daily smoker; (2) < five servings of fruits and vegetables per day; (3) low level of activity ( $<600$ MET-minutes); (4) body mass index $\geq 25 \mathrm{~kg} / \mathrm{m}^{2}$ ); (5) raised BP (SBP $\geq 140$ and/or DBP $\geq 90 \mathrm{mmHg}$ ). Participants lacking any of these were classified as low risk and those having at least three of the above-mentioned risk factors were considered as high risk of NCDs. For the definition of abdominal obesity the cutoff points of $102 \mathrm{~cm}$ in men and $88 \mathrm{~cm}$ in women were used according to the WHO.

The study was approved by the committee of ethics of the Iranian Ministry of Health and Medical Education.

\section{Results}

Participants had a nearly uniform cultural structure, comprising 98\% Turks. Most participants were housekeepers (42.4\%), $29.2 \%$ were self-employed, $10.1 \%$ were students, and $6 \%$ were government employees. Of these participants, $68.9 \%$ had a monthly income $<2$ million Rials (US\$218), 29.5\% had a monthly income of 2-7 million Rials (US\$218-763), and $1.6 \%$ had a monthly income of $\geq 7$ million Rials.

A summary of results from step 1 are given in Table 2 and results from step 2 are given in Table 3.

Combined risk factor analysis showed that $4.1 \%$ of participants were in the low-risk group (up to $5.1 \%$ among men and 3.2\% among women). Of those in the high-risk group, $25.6 \%$ were in the 25 - to 44 -year age group and $49.7 \%$ in the 45- to 64-year age group. Percentages of females were higher in both age groups.

Mean body mass index (BMI) increased with age in both sexes, at least at the first three decades of adult life (Figure 1).

Table 2 Summary of results from step I WHO STEPS approach studying risk factors of noncommunicable diseases, Ardabil, Iran 2006

\begin{tabular}{|c|c|c|c|}
\hline Results for adults aged I5-64 years $(95 \% \mathrm{Cl})$ & Males & Females & Both sexes \\
\hline \multicolumn{4}{|l|}{ Step I Tobacco use } \\
\hline Percentage who currently smoke tobacco daily & $29.0 \%$ & $2.6 \%$ & $15.7 \%$ \\
\hline \multicolumn{4}{|l|}{ For those who smoke tobacco daily } \\
\hline Average age started smoking (years) & $20.5(|9.3-2| .8)$ & $23.4(16.8-30.1)$ & $20.8(19.5-22.0)$ \\
\hline Percentage smoking manufactured cigarettes & $97.2 \%$ & $99.8 \%$ & $98.5 \%$ \\
\hline \multicolumn{4}{|l|}{ For smokers of manufactured cigarettes } \\
\hline Mean number of manufactured cigarettes smoked per day & $19.8(19.1-20.6)$ & $9.0(7.4-10.8)$ & $18.9(18.2-19.6)$ \\
\hline \multicolumn{4}{|l|}{ Step I Fruit and vegetable consumption (in a typical week) } \\
\hline Mean number of servings of fruit consumed per day & I.0 (0.9-I.I) & I.I (I.0-I.2) & I.I (I.0-I.I) \\
\hline Mean number of servings of vegetables consumed per day & I.I (I.0-I.2) & $1.2(1.1-1.3)$ & I.I (I.0-I.2) \\
\hline Percentage who ate $\geq 5$ combined servings of fruit and vegetables per day & 4.2 & 4.1 & 4.1 \\
\hline \multicolumn{4}{|l|}{ Step I Physical activity } \\
\hline Percentage with low levels of activity (defined as $<600$ MET-minutes/week) & 24.9 & 41.2 & 33.1 \\
\hline Median time spent in physical activity per day (hours) & $2.9(1.2-6.9)$ & $1.4(0.6-3.5)$ & $2.1(0.9-5.0)$ \\
\hline
\end{tabular}

Abbreviation: MET, metabolic energy. 
Table 3 Summary of results from step 2 WHO STEPS approach studying risk factors of noncommunicable diseases, Ardabil, Iran 2006

\begin{tabular}{|c|c|c|c|}
\hline Results for adults aged I5-64 years (incl. 95\% Cl) & Males & Females & Both sexes \\
\hline \multicolumn{4}{|l|}{ Step 2 Physical measurements } \\
\hline Mean body mass index (BMI, $\left.\mathrm{kg} / \mathrm{m}^{2}\right)$ & $25.3(24.9-25.7)$ & $27.9(27.4-28.4)$ & $26.6(26.3-26.9)$ \\
\hline Percentage who were overweight or obese $\left(\mathrm{BMI} \geq 25 \mathrm{~kg} / \mathrm{m}^{2}\right)$ & 51.2 & 66.5 & 58.9 \\
\hline Percentage who are obese $\left(\mathrm{BMI} \geq 30 \mathrm{~kg} / \mathrm{m}^{2}\right)$ & 14.7 & 36 & 25.6 \\
\hline Average waist circumference $(\mathrm{cm})$ & $89.4(88.2-90.5)$ & $91(89.6-92.3)$ & $90.2(89.3-91.1)$ \\
\hline Mean systolic blood pressure (SBP, mmHg) & $119.3(117.9-120.7)$ & $117.6(115.8-119.4)$ & $118.5(117.3-119.9)$ \\
\hline Mean diastolic blood pressure (DBP, $\mathrm{mmHg}$ ) & $72.9(71.8-74.1)$ & $74.0(72.8-75.2)$ & $73.5(72.7-74.3)$ \\
\hline Percentage with raised $\mathrm{BP}(\mathrm{SBP} \geq 140$ and/or $\mathrm{DBP} \geq 90 \mathrm{mmHg})$ & 14.9 & 21.3 & 18.0 \\
\hline Percentage with raised $\mathrm{BP}(\mathrm{SBP} \geq 160$ and/or $\mathrm{DBP} \geq 100 \mathrm{mmHg})$ & 4.5 & 8.4 & 6.4 \\
\hline $\begin{array}{l}\text { Percentage with isolated systolic hypertension (SBP } \geq 140 \\
\text { and } \mathrm{DBP}<90 \mathrm{mmHg} \text { ) }\end{array}$ & 3.0 & 4.4 & 3.7 \\
\hline
\end{tabular}

BMI was significantly correlated with both $\mathrm{SBP}(r=0.33$, $P<0.01)$ and DBP $(r=0.28, P<0.01)$. Abdominal obesity was observed in $14.8 \%$ of men vs $56.9 \%$ of women $(P<0.001)$. A comparison of waist circumference among age groups and between genders is shown in Figure 2.

The mean age of starting smoking was 20.5 years $(95 \%$ confidence interval [CI]: 19.3-21.8) among men and 23.4 years (95\% CI: 16.8-30.1) among women. Smoking was most prevalent among men of low-income families and those of lower education.

Figure 3 shows the percentage of participants classified into a low level of total physical activity compared with different age groups and sexes.

Mean BP, hypertension, and abdominal obesity increased with age in both groups $(P<0.01)$. The change was larger among women.

Regression analysis results showed that mean units of fruit eaten per day did not differ between sexes or among age groups (women ate only 0.12 more units of fruit per day than men $[P=0.046]$; with each 1 -year increase in age [regression coefficient: 0.002] units of fruit eaten per

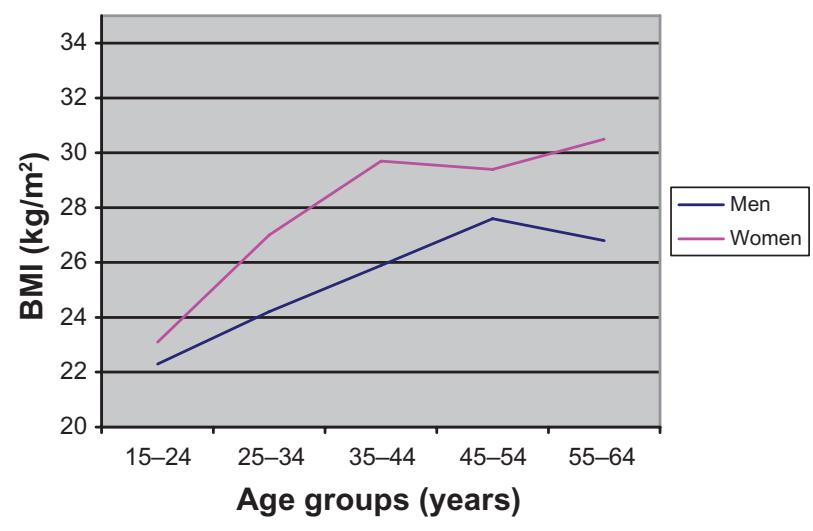

Figure I Mean body mass index (BMI) difference among different age groups. day decreased by only 0.006), although these differences were statistically significant. Mean units of vegetables eaten per day did not differ between sexes or among age groups (women ate only 0.1 units more vegetables per day than men $[P=0.58]$; with each 1 -year increase in age units, fruit and vegetables eaten per day decreased by only $0.002[P=0.19])$.

Some eating habits were correlated with mean BP. Among women, the correlation between mean BP and average days of eating fruit per week was $0.15(P<0.05)$ and the correlation between mean BP and average days of eating vegetables was $0.1(P<0.05)$. Among men only the correlation between mean BP and average days of eating vegetables was statistically significant $(r=0.1, P<0.05)$. Fruit and vegetable eating habits were not associated with abdominal obesity. Moderate activity during recreational time was negatively associated with abdominal obesity $(P<0.001)$. However, such an association was not explored for work time physical activity and abdominal obesity.

Figure 4 shows the distribution among different age groups of eating fruit or vegetables $<4$ days a week.

No sex difference was shown for consumption of fish; comparison among age groups showed that fish consumption decreased after age 35 years. Solid vegetable oil was used for cooking most often by $83.45 \%$ of people while only $14.24 \%$ used liquid oil (not significantly different between sexes or among age groups).

\section{Discussion}

In the past it was thought that CVD was confined primarily to industrialized nations, but now CVD has emerged as a major health threat in developing countries. CVD currently accounts for $30 \%$ of mortality in low- and middle-income 


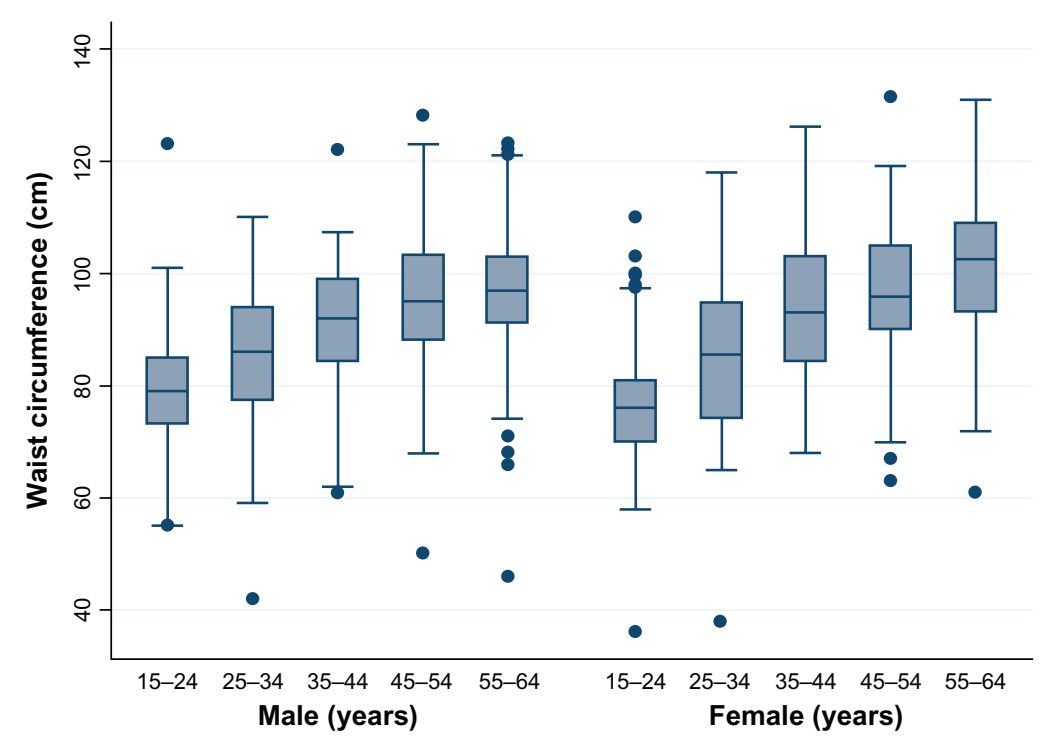

Figure 2 Box plots of waist circumference compared among age groups according to sex.

countries each year, with significant economic effects. Nevertheless, many governments and global health institutions have largely overlooked CVD. ${ }^{8}$

Nearly one-third of the men in Ardabil province were daily smokers. We found that smoking was most prevalent among men of the low-income families and those of lower education. This may indicate that, like some other developing countries, our population is in the second stage of a smoking epidemic and we may expect even higher mortality and morbidity during the coming decades..$^{9,10}$

Considering the governing role of men at Iranian households especially in rural areas, this result should also raise concerns about the effect of passive smoking on others, particularly children. This problem is exacerbated by the fact that it occurs mostly among people of lower education and income, who live in low-roofed houses and are unaware of the risks of passive smoking.

The overall prevalence of current smokers was $15.7 \%$, higher than studies conducted with a similar methodology in neighboring provinces as well as the country as a whole. ${ }^{11,12}$ But it was much lower than in a study carried out using WHO STEPS in Indonesia, in which $54 \%$ of men and $27.6 \%$ of the total population were current daily smokers. The main difference in methodology was that the Indonesian study enrolled an age range of 15-74 years, but this may not adequately explain the different results. Another study in 1998 in Turkey,

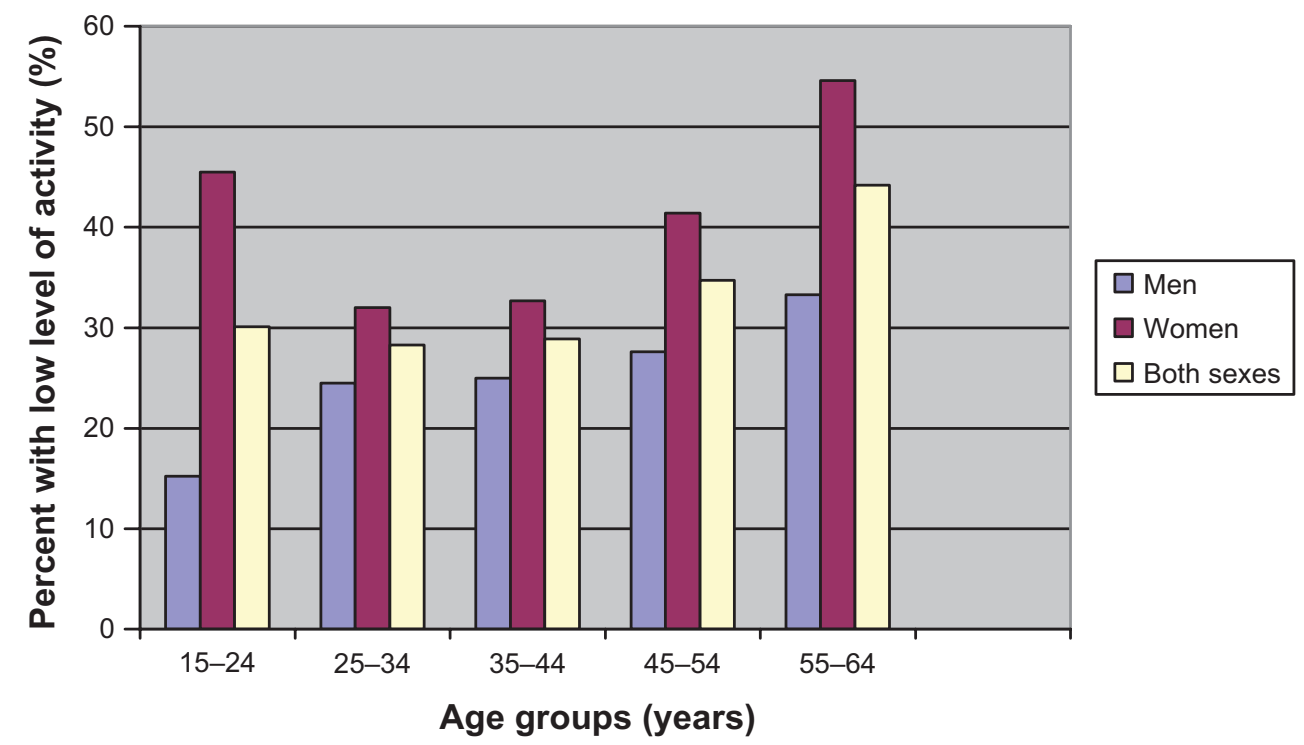

Figure 3 Percentage of participants classified into low level of total physical activity compared between sexes and among age groups. 


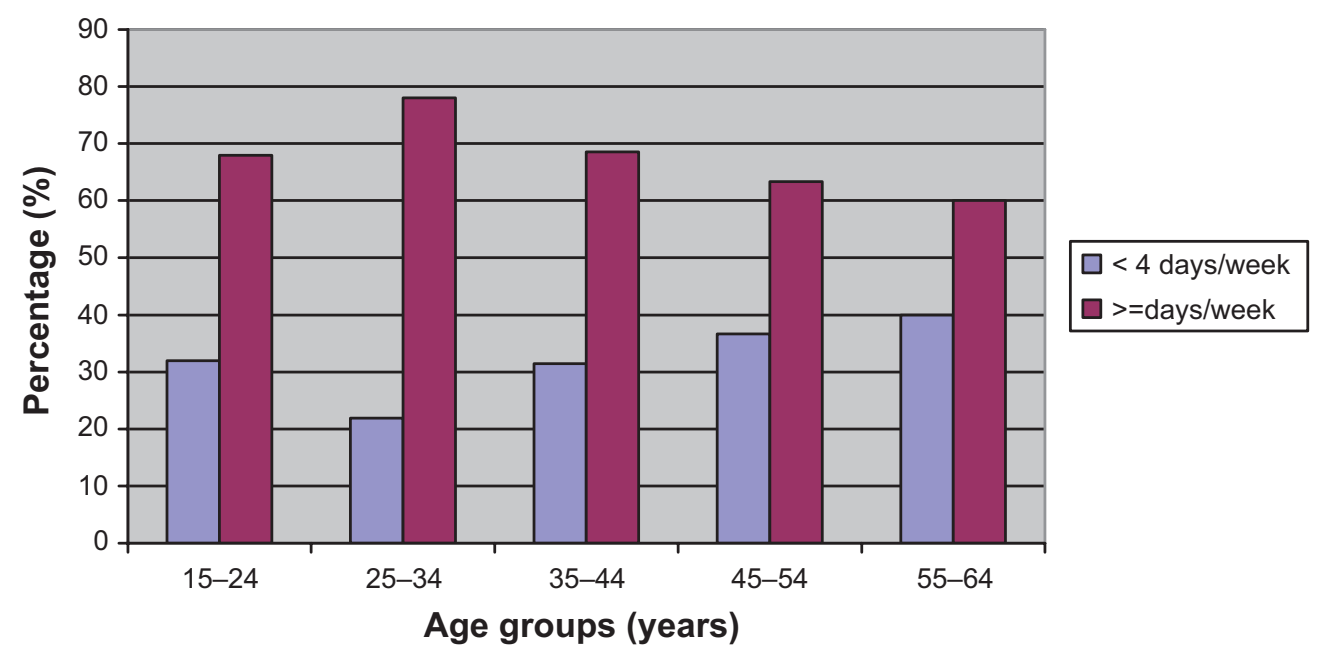

Figure 4 Distribution of eating fruit or vegetables $<4$ days a week in different age groups.

which is a northern neighbor of Iran and has an approximately equal population, showed that $49.7 \%$ of men and $11.8 \%$ of women were daily smokers. ${ }^{10,13}$

Nearly one-third of the population in our study had a low level of physical activity, which was higher among women and higher age groups. Similar results were found in a nearby study, in east Azerbaijan. ${ }^{11}$ Those having higher activity also had lower BMI. Such an association is in line with previous studies. ${ }^{14-18}$

The obesity prevalence was $25.5 \%$. Although the figure is a little higher than in neighboring provinces and than national figures, it lies in a range reported by other Iranian studies and in some developing countries. Similar to our findings, other studies have also shown that obesity is less common in early

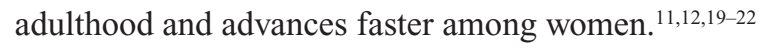

Mean BMI (Figure 1) increased with age in the first three decades of age among men, then, after a plateau, it continued to increase at a slower rate. For women the increase continued for a little longer, but then declined after 54 years of age. The trend in women may be explained by the effects of aging, such as lower intake of food, or declining uptake of nutrients due to gastrointestinal dysfunction or even changed metabolism. Another plausible mechanism may be the lower life span of obese people, reducing their chance of being included in the sample. But in men the late BMI increase, which is contrary to expectations, can be explained by the fact that men stay at home more when they get old. Here they have easier access to food and compensate for lack of the distraction of work by wandering around the house eating and/or drinking. Some similar results have been published previously..$^{14,16,20,23}$
In this study $18 \%$ of people had at least mild hypertension, lower than a study conducted in east Azerbaijan. ${ }^{11}$ In a national study in Iran the overall prevalence of systolic, diastolic as well as systolic or diastolic hypertension were $4.2 \%, 5.4 \%$, and $7.7 \%$, respectively, with no significant sex difference. ${ }^{24}$ Mean SBP and DBP in our study were 118.5 and $73.5 \mathrm{mmHg}$, respectively. In a study with similar methodology based on WHO STEPS conducted in three Asian and African countries, mean SBP varied from 117 to $127 \mathrm{mmHg} .{ }^{25}$

BMI in our study was significantly correlated with SBP and DBP, which was consistent with the WHO STEPS study in Asian and African countries. ${ }^{25}$

Americans are known for their bad eating habits. American adults are 24\% more likely to be overweight/ obese and $59 \%$ more likely to be inactive in leisure time than Canadians. ${ }^{26}$ Interestingly, one study has found that obesity, overweight, and hypertension in Iran is as prevalent as in the US, but Iranian women are more obese than American women while a reverse pattern was found in males. This is also in line with our study, indicating that health policy makers should consider this gender discrepancy as a major issue to be addressed. ${ }^{27}$

Mean daily servings of both fruit and vegetables were both 1.1 in this study, which is reasonable compared with those in some other countries. Fruit and vegetable consumption has always been an important scientific health recommendation. ${ }^{28}$ Gaskin's study showed that $62 \%$ ate two or fewer servings of fruits or vegetables daily. ${ }^{29} \mathrm{By}$ secondary exploratory analysis we also found inter-correlations among the studied risk factors; for example, some eating habits and 
physical activities were correlated with BP. Although these were in line with results of other studies, ${ }^{30-32}$ such associations need to be more specific, and detailed methodology need to be addressed. Newly developed statistical models that have been suggested for use in public health research could enable such complex associations of large numbers of variables to be explored. ${ }^{33-35}$

One methodological issue we encountered during the data collection phase was that in the WHO-based questionnaire assessing the number of days people eat vegetables and fruits, 5 and 6 days seemed to be underestimated and 7 days seemed to be overestimated. We think this may not reflect reality, possibly because people may prefer to choose the highest score of a bounded scale if they feel their score is close to the upper boundary. This may affect the distribution of the scale of interest. However, to prevent biased test results we used nonparametric methods in such cases.

Our findings provide evidence for health policy-makers as well as municipalities about lifestyle problems in a studied population. A burden of more diseases is expected if an effective prevention strategy is not undertaken. Although even shortterm educational programs have been shown to be effective in improving lifestyle, a durable education strategy and costsaving policies supported by sustained mass media education and school-based educational programs can be the starting point for a possible national program on controlling NCDs. ${ }^{28,36-38}$

\section{Disclosure}

The authors report no conflicts of interest in this work.

\section{References}

1. Sen K, Bonita R. Global health status: two steps forward, one step back. Lancet. 2000;356(9229):577-582.

2. World Health Organisation. NCD mortality and morbidity. http:// www.who.int/gho/ncd/mortality_morbidity/en/. 2011. Accessed 20 June, 2011.

3. World Health Organisation. Global strategy for non-communicable disease prevention and control. Geneva, Switzerland: World Health Organisation; 1997.

4. World Health Organisation. The world health report 2003-Shaping the future. Geneva, Switzerland: World Health Organisation; 2003.

5. Murray CJL, Lopez AD. The global burden of disease: a comprehensive assessment of mortality and disability from diseases, injuries and risk factors in 1990 and projected to 2020. Cambridge, UK: Harvard University Press; 1996.

6. Sadi-Lari M, Sayyari AA, Akbari ME, Gray D. Public health improvement in Iran-lessons from the last 20 years. Public Health. 2004;118(6):395-402

7. Bonita R, Decourten M, Dwyer T, Jamrozic K, Winkelmann R. Surveillance of risk factors for noncommunicable diseases: the WHO STEPwise approach. Geneva, Switzerland: World Health Organisation; 2002.

8. Fuster Y, Kelly B. Promoting Cardiovascular Health in the Developing World: a critical challenge to achieve global health. Washington, D.C: The National Academies Press; 2010.
9. Lopez A, Collishaw N, Piha T. A descriptive model of the cigarette epidemic in developed countries. Tob Control. 1994;3(3):242-247.

10. Ng N, Stenlund H, Bonita R, Hakimi M, Wall S, Weinehall L. Preventable risk factors for noncommunicable diseases in rural Indonesia: prevalence study using WHO STEPS approach. Bull World Health Organ 2006;84(4):305-313.

11. Seyffarshad M, Kousha A, Pourdowlati M, et al. Cardiac risk factor analysis in east Azerbaijan, Iran. The cardiology. 2007;3(1):1-4.

12. Iranian MOH. National NCD Health Survey 2005. Tehran, Iran: center for disease control, Iranian Ministry of Health; 2002.

13. Bozkurt AI, Sahinoz S, Ozcirpici B, et al. Patterns of active and passive smoking, and associated factors, in the South-east Anatolian Project (SEAP) region in Turkey. BMC Public Health. 2006;6:15.

14. Kelishadi R, Alikhani S, Delavari A, Alaedini F, Safaie A, Hojatzadeh E. Obesity and associated lifestyle behaviours in Iran: findings from the First National Non-communicable Disease Risk Factor Surveillance Survey. Public Health Nutr. 2007;12:1-6.

15. Kelishadi R, Ardalan G, Gheiratmand R, et al. Association of physical activity and dietary behaviours in relation to the body mass index in a national sample of Iranian children and adolescents: CASPIAN Study. Bull World Health Organ. 2007;85(1):19-26.

16. Sibai AM, Hwalla N, Adra N, Rahal B. Prevalence and covariates of obesity in Lebanon: findings from the first epidemiological study. Obes Res. 2003;11(11):1353-1361.

17. Slattery ML, Sweeney C, Edwards S, et al. Physical activity patterns and obesity in Hispanic and non-Hispanic white women. Med Sci Sports Exerc. 2006;38(1):33-41.

18. Ismail MN, Chee SS, Nawawi H, Yusoff K, Lim TO, James WP. Obesity in Malaysia. Obes Rev. 2002;3(3):203-208.

19. Dastgiri S, Mahdavi R, TuTunchi H, Faramarzi E. Prevalence of obesity, food choices and socio-economic status: a cross-sectional study in the north-west of Iran. Public Health Nutr. 2006;9(8):996-1000.

20. Hajian-Tilaki KO, Heidari B. Prevalence of obesity, central obesity and the associated factors in urban population aged 20-70 years, in the north of Iran: a population-based study and regression approach. Obes Rev. 2007;8(1):3-10.

21. Rashidi A, Mohammadpour-Ahranjani B, Vafa MR, Karandish M. Prevalence of obesity in Iran. Obes Rev. 2005;6(3):191-192.

22. Al-Mahroos F, Al-Roomi K. Overweight and obesity in the Arabian Peninsula: an overview. J R Soc Health. 1999;119(4):251-253.

23. Williamson DF. Descriptive epidemiology of body weight and weight change in US adults. Ann Intern Med. 1993;119(7 Pt 2):646-649.

24. Kelishadi R, Ardalan G, Gheiratmand R, et al. Blood pressure and its influencing factors in a national representative sample of Iranian children and adolescents: the CASPIAN Study. Eur J Cardiovasc Prev Rehabil. 2006;13(6):956-963.

25. Tesfaye F, Nawi NG, Van MH, et al. Association between body mass index and blood pressure across three populations in Africa and Asia. J Hum Hypertens. 2007;21(1):28-37.

26. Hart TL, Craig CL, Griffiths JM, et al. Markers of sedentarism: the joint Canada/US. Survey of health. J Phys Act Health. 2011;8(3): 361-371.

27. Bahrami H, Sadatsafavi M, Pourshams A, et al. Obesity and hypertension in an Iranian cohort study; Iranian women experience higher rates of obesity and hypertension than American women. $B M C$ Public Health. 2006;6:158.

28. Lichtenstein AH, Appel LJ, Brands M, et al. Diet and lifestyle recommendations revision 2006: a scientific statement from the American Heart Association Nutrition Committee. Circulation. 2006;114(1):82-96.

29. Gaskins ND, Sloane PD, Mitchell CM, Ammerman A, Ickes SB, Williams CS. Poor nutritional habits: a modifiable predecessor of chronic illness? A North Carolina Family Medicine Research Network (NC-FM-RN) study. J Am Board Fam Med. 2007;20(2):124-134.

30. Camoes M, Oliveira A, Pereira M, Severo M, Lopes C. Role of physical activity and diet in incidence of hypertension: a population-based study in Portuguese adults. Eur J Clin Nutr. 2010;64(12):1441-1449. 
31. Azadbakht L, Surkan PJ, Esmaillzadeh A, Willett WC. The Dietary Approaches to Stop Hypertension Eating Plan Affects C-Reactive Protein, Coagulation Abnormalities, and Hepatic Function Tests among Type 2 Diabetic Patients. J Nutr. 2011;141(6):1083-1088.

32. Esposito K, Giugliano D. Beneficial effects of a Dietary Approaches to Stop Hypertension eating plan on features of the metabolic syndrome. Diabetes Care. 2006;29(4):954-955.

33. Sadeghi BH, Arshi S, Ekman R, Mohammadi R. Prevention-oriented epidemiology of burns in Ardabil provincial burn centre, Iran. Burns. 2011;37(3):521-527.

34. Sadeghi-Bazargani H, Shrikant B, Mohammadi R, Mohammad K. Application of the new OPLS-DA statistical modeling technique to manage large number of variables in a burn injury case control study. 3rd meeting of the EURO Working Group on Stochastic Modelling. Naflpio; 2010.
35. Eriksson L, Johansson E, Wold N, Trygg J, Wikstrom C, Wold S. Multi- and Megavariate Data Analysis: Advanced Applications and Method Extensions. 1st ed. Umea, Sweden: Umetrics AB; 2006.

36. Pazoki R, Nabipour I, Seyednezami N, Imami SR. Effects of a community-based healthy heart program on increasing healthy women's physical activity: a randomized controlled trial guided by Community-based Participatory Research (CBPR). BMC Public Health. 2007;7:216.

37. Sartorelli DS, Sciarra EC, Franco LJ, Cardoso MA. Beneficial effects of short-term nutritional counselling at the primary health-care level among Brazilian adults. Public Health Nutr. 2005;8(7):820-825.

38. Story M, Kaphingst KM, French S. The role of schools in obesity prevention. Future Child. 2006;16(1):109-142.

\section{Publish your work in this journal}

Vascular Health and Risk Management is an international, peerreviewed journal of therapeutics and risk management, focusing on concise rapid reporting of clinical studies on the processes involved in the maintenance of vascular health; the monitoring, prevention and treatment of vascular disease and its sequelae; and the involvement of metabolic disorders, particularly diabetes. This journal is indexed on PubMed Central and MedLine. The manuscript management system is completely online and includes a very quick and fair peer-review system, which is all easy to use. Visit http://www.dovepress.com/ testimonials.php to read real quotes from published authors. 